\title{
Involvement of Brn3a-positive spinal dorsal horn neurons in the transmission of visceral pain in inflammatory bowel disease model mice
}

Kazuhiko Nishida*, Shinji Matsumura, and Takuya Kobayashi

Department of Medical Chemistry, Kansai Medical University, Shinmachi 2-5-1,

Hirakata, Osaka 573-1010, Japan

*Corresponding author, Tel: +81 72804 2342; Fax: +81 72804 2349, E-mail address:

nishidka@hirakata.kmu.ac.jp

Keyword: visceral pain, spinal dorsal horn, Brn3a

Short title: Involvement of Brn3a-positive spinal neurons in visceral pain transmission 


\section{Abstract}

Spinal dorsal horn plays crucial roles in the transmission and processing of somatosensory information. Although spinal neural circuits which process several distinct types of cutaneous sensation have been extensively studied, those responsible for visceral pain transmission remain poorly understood. In the present study, we analyzed the dextran sodium sulfate (DSS)-induced inflammatory bowel disease (IBD) model mice to characterize the spinal dorsal horn neurons involved in visceral pain transmission. DSS-treated mice exhibited increased abdominal licking behavior, suggestive of experiencing visceral pain. Immunostaining of c-fos, a marker indicating neuronal activity, demonstrated that numerous c-fos-positive cells were found bilaterally in the lumbosacral spinal dorsal horn, and their distribution was particularly abundant in the shallow dorsal horn. Neurochemical characterization of these neurons revealed that the percentage of the POU transcription factor Brn3a-positive neurons among the c-fos-positive neurons in the shallow dorsal horn was $30-40 \%$ in DSS-treated mice, which was significantly higher than that in the somatic pain model mice. We further demonstrated by neuronal tracing that within the shallow dorsal horn, Brn3a-positive neurons are represented more highly in spino-solitary projection neurons than in spino-parabrachial projection ones. These results raised the possibility that 
Brn3a-positive spinal dorsal horn neurons make a large contribution to visceral pain transmission, and part of which was mediated through spino-solitary pathway. 


\section{Introduction}

Sensory signal from internal organs is crucial for monitoring visceral disorders

such as inflammation or mechanical distention. Such visceral information is conveyed

to higher brain centers via the spinal cord and the vagus nerve, with the spinal cord

pathway commonly assumed to transmit pain [1]. Within the spinal cord, the dorsal horn

in particular plays pivotal roles in processing sensory signals and their transmission to

the higher brain center, which are mediated by heterogeneous populations of

interneurons and supraspinal projection neurons, respectively. A number of studies on

the spinal sensory transmission indicate that distinct neuronal populations process

different somatosensory modalities, such as mechanical pain, heat, and itch [2]. Visceral

pain is recognized as a sensation differing from somatic pain (e.g. diffused pain

localization and occasional induction of referred pain and autonomic reflex) [3]. It is

highly possible that visceral and somatic pain is processed by distinct neuronal circuits

in the spinal dorsal horn. This notion has been confirmed by previous studies on the

neuronal activity patterns in the spinal dorsal horn in response to visceral and somatic

stimulations. Visceral stimulation evokes activities of spinal neurons primarily in the

marginal (lamina I) and deeper (lamina $\mathrm{V}$ and $\mathrm{X}$ ) laminae as well as in the

parasympathetic nucleus [4-7]. On the other hand, somatic stimulation evokes spinal 
neurons broadly distributed across laminae of the spinal dorsal horn (lamina I-V) [4, 5].

There have been controversial reports in terms of response specificity of spinal dorsal horn neurons. Cervero and colleagues reported that most spinal dorsal horn neurons in lamina I and V responsive to visceral stimulation also received somatic sensory inputs $[4,8]$. By contrast, Luz et al. recently showed that lamina I neurons in the spinal dorsal horn is comprised of visceral-, somatic-, and viscero-somatic-responsive neurons [9], suggesting that somatic and visceral pain might be processed by distinct neuronal circuits. The ascending spinal pathway necessary for visceral pain transmission to the higher brain center has been the subject of several studies. A population of supraspinal projection neurons in the marginal lamina were shown to respond to visceral stimulation but not somatic one [9]. In addition, post synaptic dorsal column (PSDC) neurons, the other subtypes of supraspinal projection neurons, have been shown to play a critical role in the visceral pain transmission to the gracile nucleus in the medulla $[10,11]$. While we know a bit more on the distribution pattern and morphological feature of visceral pain responsive neurons in the spinal dorsal horn, we still know very little about the neurochemical identity of these neurons, which hampers the understanding of spinal neural circuits for visceral pain transmission.

In the present study, we employed DSS-treated inflammatory bowel disease 
(IBD) model mice as a possible model for visceral pain. Analysis of neuronal activity in the lumbosacral spinal cord revealed that Brn3a-positive neurons in the marginal lamina were preferentially activated under visceral pain condition compared to somatic one. We also showed that Brn3a-positive neurons responsive to visceral pain is involved in the viscero-sensory transmission to the nucleus of the solitary tract (NTS). 


\section{Materials and methods}

\section{Animals}

C57BL/6J mice (CLEA Japan Inc., Tokyo, Japan) were maintained on a $12 \mathrm{~h}$ (8:00 A.M. to 8:00 P.M.) light-dark schedule. All animal experiments were conducted in accordance with Japanese guidelines and regulations (2006) for scientific and ethical animal experimentation and approved by the Animal Experimentation Committee of Kansai Medical University (21-037).

\section{Induction of experimental colitis}

Seven- to nine-week-old mice of either sex were treated with drinking water containing 2\% DSS (molecular weight: 36000-50000, MP Biomedicals, Illkirch, France) or regular drinking water as a control. Mice were treated with DSS containing water for 7-8 days until their body weight were reduced $10-20 \%$ compared to that before treatment. Behavioral test was performed 6 days after DSS treatment. For behavioral test, DSS-treated and control mice were placed on a wire mesh enclosed by an acrylic wall $(10 \mathrm{~cm}$ in length and width, and $30 \mathrm{~cm}$ in height). Following habituation for $20 \mathrm{~min}$, behavior of the mice was videotaped for $30 \mathrm{~min}$. Duration and number of abdominal licking behaviors, which are commonly observed in mice experiencing visceral pain [12], was analyzed. 


\section{Induction of cutaneous pain by formalin injection}

For application of cutaneous pain onto the skin, formalin was injected into the lower back skin on the right side, which is between the roots of tail and lower limb of the mouse. Primary sensory neurons responsible for this skin area project to the spinal dorsal horn at L6 to S1 segments [13] where visceral pain inputs in DSS-treated mice were found in the present study. Hair of the skin around this area was removed using an electric shaver one day before injection. Following brief anesthesia using isoflurane, 10 $\mu 1$ of $5 \%$ formalin was injected into the skin using a 30-gauge needle attached to Hamilton syringe. Two hours after injection, the mice were perfused to obtain the spinal cord samples.

\section{Immunohistochemistry and in situ hybridization}

DSS-treated and formalin-injected mice were transcardially perfused with $0.1 \mathrm{M}$ phosphate buffer $(\mathrm{pH}$ 7.4) containing $4 \%$ paraformaldehyde following anesthesia with pentobarbital (50 mg/kg, Nakalai Tesque, Kyoto, Japan), and their spinal cords were subsequently dissected out. Following post-fixation for $3 \mathrm{~h}$, the samples were immersed overnight at $4^{\circ} \mathrm{C}$ in $0.1 \mathrm{M}$ phosphate-buffered saline (PBS) containing 30\% (w/w) 
sucrose. Before the sample was frozen, spinal cord samples were notched so that L4 to S1 spinal segments could be distinguished in later analyses. The spinal cords were then embedded in OCT compound (Sakura Finetek, Tokyo, Japan), and kept at $-80^{\circ} \mathrm{C}$ until examined.

Transverse sections of the lumbosacral spinal cord of the mice were prepared by using a cryostat (20- $\mu \mathrm{m}$ sections). Immunohistochemistry on the spinal dorsal horn sections was described previously [14]. Antibodies used in the current study are goat anti-c-fos (1:200, Santa Cruz Biotechnology, Dallas, TX, USA, sc-52), rabbit anti-c-fos (1:500, Synaptic Systems, Goettingen, Germany, 226003), mouse anti-Brn3a (1:300, Sigma, St. Louis, MO, USA, MAB1585), rabbit anti-Pax2 (1:500, Thermo Fisher Scientific Inc., Waltham, MA, USA, 71-6000), goat anti-cholera toxin B (CTB, 1:5000, List Biological Laboratories, Campbell, CA, USA, 703), rabbit anti-PKC $\gamma(1: 100$, Santa Cruz Biotechnology, sc-211), Alexa 594-conjugated donkey anti-goat IgG (1:300, Invitrogen, Carlsbad, CA, USA, A11058), Alexa 594-conjugated goat anti-mouse IgG (1:300, Invitrogen, A11032), Alexa 488-conjugated donkey anti-mouse IgG (1:300, Invitrogen, A21202), Alexa 488-conjugated donkey anti-rabbit IgG (1:300, Invitrogen, A21206), and Cy5-conjugated donkey anti-mouse IgG antibodies (1:300, Jackson ImmunoResearch, West Grove, PA, USA, 715-175-150). 
In situ hybridization coupled with immunostaining was performed as described previously [15] with some modifications. cDNAs for mouse somatostatin (SST, 15-528 of NM_009215), mouse preprodynorphin (Pdyn, 1-747 of NM_018863), mouse cholecystokinin (CCK, 3-688 of NM_031161) were PCR-amplified and subcloned into the pGEMTEZ vector (Promega, Fitchburg, WI, USA). Digoxigenin (DIG)-labeled anti-sense probes were prepared by using DIG-labeled 11-UTP (Sigma), RNA polymerase (Sigma), and template cDNAs, and purified by Clean-Up columns (Sigma). Transverse sections of the spinal cord were post-fixed for $15 \mathrm{~min}$, washed by DEPC-treated $\mathrm{dH}_{2} \mathrm{O}$, and incubated with $0.3 \% \mathrm{H}_{2} \mathrm{O}_{2}$ for 10 min to inactivate endogenous peroxidase. After washing with DEPC-treated $\mathrm{dH}_{2} \mathrm{O}$, they were incubated for 10 min with $0.1 \mathrm{M}$ triethanol amine ( $\mathrm{pH} 8.0$ ) including $0.25 \%$ acetic anhydride. The sections were then incubated at $60^{\circ} \mathrm{C}$ for $1 \mathrm{~h}$ in hybridization buffer containing $50 \%$ formamide, 5 x SSPE ( $\mathrm{pH} 7.4$ ), 1 x SDS, $0.4 \mathrm{mg} / \mathrm{ml}$ yeast tRNA (Sigma). Then, they were transferred to the above hybridization buffer containing DIG-labeled riboprobe that had been heat-denatured at $80^{\circ} \mathrm{C}$ for 5 min in advance, and were kept at $60^{\circ} \mathrm{C}$ overnight. The sections were washed 3 times at $60^{\circ} \mathrm{C}$ for $30 \mathrm{~min}$ with hybridization wash buffer (50\% formamide, $2 \times \mathrm{SSC}[\mathrm{pH} 7.0])$ and subsequently 3 times at room temperature for $5 \mathrm{~min}$ with Tris-buffered saline (TBS, $\mathrm{pH} 7.5$ ) containing $0.1 \%$ 
Tween-20. Following blockage with TNB blocking reagent (PerkinElmer, Waltham, MA, USA) for $1 \mathrm{~h}$, the sections were incubated with TNB blocking reagent containing peroxidase-conjugated sheep anti-DIG antibody (1:1000, Sigma, 11207733910) at room temperature for $2 \mathrm{~h}$. After washing with TBS containing $0.1 \%$ Tween-20, the sections were incubated with Tyramide-conjugated $\mathrm{Cy} 3$ or fluorescein $(1: 75$, PerkinElmer) at room temperature for $20 \mathrm{~min}$ to visualize the in situ signal. After washing with PBS containing $0.2 \%$ Triton X-100, they were further incubated with blocking solution (PBS containing $0.2 \%$ Triton $\mathrm{X}-100$ and $2 \% \mathrm{BSA}$ ) at room temperature for $1 \mathrm{~h}$, followed by incubation with rabbit anti-c-fos antibody (Synaptic Systems) or mouse anti-Brn3a antibody (Sigma) in blocking solution at $4^{\circ} \mathrm{C}$ overnight. Thereafter, they were incubated with Alexa 488-conjugated donkey anti-rabbit $\operatorname{IgG}(1: 300$, Invitrogen) or Alexa488-conjugated donkey anti-mouse IgG (1:300, Invitrogen) to visualize c-fos or Brn3a signals, respectively.

The sections were counterstained with Hoechst 33342 (1:2000, Thermo Fisher Scientific Inc.) and were mounted with mounting reagent containing $25 \%$ glycerol, 0.1 M Tris (pH 8.5), $27.5 \mathrm{mg} / \mathrm{ml}$ 1,4-Diazabicyclo[2.2.2]octane (DABCO, Tokyo Chemical Industry Co., Tokyo, Japan), and $100 \mathrm{mg} / \mathrm{ml}$ Mowiol 4-88 (Merck, Darmstadt, Germany); and fluorescent images were then obtained with a confocal microscope 
(LSM700, Carl Zeiss, Jena, Germany).

\section{Retrograde labeling of supraspinal projection neurons by}

\section{CTB}

CTB injection into the lateral parabrachial nucleus was described previously

[14]. For CTB injection into the nucleus of the solitary tract (NTS), a fine glass capillary (tip diameter: $\sim 50 \mu \mathrm{m}$ ) connected with Hamilton syringe was used. Following anesthesia with a mixture of medetomidine $(37.5 \mu \mathrm{g} / \mathrm{kg}$, Nippon Zenyaku Kogyo, Fukushima, Japan), midazolam (2 mg/kg, Sandoz, Tokyo, Japan), and butorphanol (0.25 mg/kg, Meiji Seika Pharma, Tokyo, Japan), 7- to 9-week-old mice were fixed in a stereotactic apparatus (SR-5M-HT, Narishige, Tokyo, Japan), and a burr hole was made in the skull of the mice over the injection site (bregma -8.0, lateral 0) by a dental drill. A Glass capillary filled with $1 \%$ CTB (Sigma) was inserted into the brain $4.0 \mathrm{~mm}$ below the brain surface, and $400 \mathrm{nl}$ of CTB solution was injected into the brain by a microinjector (IMS-20, Narishige) attached to a stereotactic apparatus. Six days after CTB injection, the mice were transcardially perfused to obtain spinal cord and hindbrain samples. Because the nucleus of the solitary tract is localized around the midline of the medulla, CTB injection labeled both the right and the left sides of the nucleus. Thus, 
retrogradely labeled lamina I spino-solitary neurons on both sides were analyzed in this study.

For labeling of spino-solitary supraspinal projection neurons in DSS-treated mice, CTB was first injected into NTS, and treatment with $2 \%$ DSS started 2 days later. Nine to ten days after CTB injection, the mice were transcardially perfused to obtain spinal cord and hindbrain samples for further analysis.

\section{Image analysis}

For the analysis of global distribution pattern of c-fos-positive cells in control,

DSS-treated, and formalin-injected mice, several fluorescence images covering the entire spinal cord section were taken by a confocal microscope (LSM700), and were stitched together to obtain whole images. Darkfield photos were also taken to distinguish the boundary between the white and gray matter. ImageJ was used for measurement of the fluorescence intensity. Transverse sections of spinal cords are divided into 4 regions in this study, shallow dorsal horn (SDH), deep dorsal horn (DDH), ventral horn $(\mathrm{VH})$, and lateral funiculus (LF). Dorsal and ventral horns (VH) were defined as areas of gray matter dorsal and ventral to the central canal, respectively. 
Dorsal horn was further divided into SDH and DDH by a line between the ventral edge of the dorsal funiculus and the medial edge of LF in the intermediate spinal cord.

For the analysis of signal intensity of several markers among c-fos-positive or Brn3a-positve neurons, fluorescence images were captured every $2 \mu \mathrm{m}$ along z-axis, and average fluorescence intensity was measured by Imaris (Oxford instruments, Abington-on-Thames, UK). c-fos-positive neurons whose average c-fos signal intensity was above 5000 and 10000 were defined as c-fos and c-fos-H cells, respectively. For the quantification of Pax2 and Brn3a signals, the average intensity which was 2 times stronger than that of the background level was regarded as a positive signal. For the quantification of somatostatin and preprodynorphin signals, the average intensity which was 3 times stronger than that of the background level was regarded as a positive signal.

\section{Statistical analyses}

The results of animal behavior and histochemistry were analyzed by Mann-Whitney U test. All statistical analyses were performed by using GraphPad Prism 7.02 (GraphPad Software, Inc., La Jolla, CA, USA). The data were expressed as the mean \pm SEM 


\section{Results}

\section{Behavioral analysis of DSS-treated mice}

IBD exhibits an inflammation of the gastrointestinal tract, which is often accompanied by chronic abdominal pain in human [16]. In order to investigate spinal neuronal circuits involved in visceral pain transmission, we induced IBD in mice by treatment with water containing DSS as a possible model for visceral pain. C57BL/6J mice were used in this study because their sensitivity to DSS treatment is high enough to cause severe inflammation [17] and evoke neuronal activities in the spinal dorsal horn [18]. Mice treated with 2\% DSS exhibited occult blood in stool and diarrhea from $4^{\text {th }}$ day, followed by body weight loss (Fig. 1A). Since abdominal licking is one of the typical behaviors of mice experiencing visceral pain [12], we therefore assessed this behavior of the mice by video recordings on the $6^{\text {th }}$ day. This analysis demonstrated that these mice exhibited increased number (Pre: $4.4 \pm 1.3[n=7$ mice], Post: $15.6 \pm 3.0[n=$ 7 mice]) and duration (Pre: $22.1 \pm 4.8 \mathrm{~s}[n=7$ mice], Post: $105.3 \pm 17.5 \mathrm{~s}[n=7$ mice $]$ ) of abdominal licking behavior post-DSS-treatment compared with pre-DSS-treatment (Fig. 1B and 1C). These results suggest that DSS treatment is a valid method to generate visceral pain mouse model. 


\section{Neural activity in the spinal cord of DSS-treated mice}

To directly assess whether spinal dorsal horn receives visceral sensory inputs in

mice treated with DSS, we analyzed global distribution of neuronal activities in the spinal cord of the mice by c-fos immunostaining. For this analysis, DSS-treated mice with 10 to $20 \%$ decrease in body weight compared with pretreatment time were used. The reduction of body weight to this extent typically took 7 to 8 days following DSS treatment (Fig. 1A). Mice in this condition is hereafter referred to as "DSS-treated mice". c-fos immunostaining of the spinal cord sections of DSS-treated mice showed numerous c-fos-positive-neurons bilaterally in the lumbosacral spinal cord, with the abundance highest between L6 and S1 spinal segments (Fig. 2). These spinal segments corresponds to the central target area of pelvic afferents from the distal colon [19]. In comparison, spinal cord sections from control mice showed only a few c-fos-positive neurons. $64.1 \pm 3.6 \%$ ( $n=4$ mice, 1205 cells) of c-fos-positive neurons in DSS-treated mice were found in the shallow dorsal horn $(\mathrm{SDH})$, with the rest distributed in the deep dorsal horn (DDH), lateral funiculus (LF), and ventral horn (VH) (Fig. 2C). Abundance of c-fos-positive neurons in the SDH prompted us to further analyze their detailed distribution within SDH. To this end, we analyzed the laminar localization of c-fos-positive neurons in the SDH by co-immunostaining with $\mathrm{PKC} \gamma$ (Fig. 2D-G), a 
marker of neurons at lamina II-III border [2]. Within SDH, c-fos-positive neurons were commonly found in the marginal lamina (lamina I) throughout segments, with some of those scattered in lamina IIo to III in the more caudal segments $(\sim \mathrm{S} 1)$. Taken together, these results suggest that visceral pain signal in DSS-treated mice is transmitted mainly in the SDH of the spinal cord around L6 to S1 segments.

\section{Characterization of c-fos-positive neurons in DSS-treated mice}

Neurochemical characterization of visceral pain-responsive neurons in the spinal cord would provide clues to understand neural circuits for visceral pain transmission. We thus characterized c-fos-positive neurons in DSS-treated mice by co-immunostaining with several markers (Fig. 3A-I). SST marks $\sim 60 \%$ of excitatory interneurons in laminae I-II of the spinal dorsal horn [20]. We performed immunostaining of c-fos together with in situ hybridization of SST (Fig. 4A-C), and demonstrated that $17.6 \pm 1.7 \%$ ( $n=6$ mice, 573 cells $)$ of c-fos-positive cells were $S S T$-positive. Among those with strong c-fos intensity (c-fos-H), $21.2 \pm 2.2 \%(n=6$ mice, 230 cells) were SST-positive. We next performed immunostaining of Pax2 (Fig. 3D-F), a marker of GABAergic inhibitory interneurons throughout the spinal dorsal 
horn [21]. This analysis demonstrated that $31.8 \pm 1.4 \%(n=5$ mice, 1548 cells $)$ of c-fos-positive cells and $42.0 \pm 1.4 \%$ ( $n=5$ mice, 488 cells) of c-fos-H-positive ones were Pax2-positive, which were comparable to the abundance of inhibitory neurons in the SDH [22]. Preferential distribution of c-fos-positive neurons in the marginal lamina of the spinal dorsal horn in DSS-treated mice (Fig. 2D-G) prompted us to characterize these neuronal population by a marker of the marginal lamina neurons. Brn3a is expressed in the marginal lamina as well as deeper laminae of the spinal dorsal horn at both developmental and adult stages [23], and it can be used as a marker of marginal lamina neurons in the SDH. We thus performed immunostaining using antibodies against c-fos together with Brn3a in DSS-treated mice (Fig. 3G-I). This analysis showed that $30.4 \pm 2.6 \%(n=5$ mice, 1141 cells $)$ of c-fos-positive cells and $38.1 \pm 5.3 \%(n=5$ mice, 324 cells) of c-fos-H-positive ones were Brn3a-positive.

To understand the differences of neural circuits mediating visceral versus somatic pain, we compared our visceral pain model with the somatic pain model mice. Somatic pain model was generated by subcutaneous injection of formalin into the lower back skin so that somatic pain signal is introduced into L6 to S1 spinal segments (See materials and methods in detail). Overall distribution of c-fos positive neurons in formalin-injected mice was comparable to that in DSS-treated mice, except that 
c-fos-positive neurons were distributed almost exclusively on the formalin-injected side, and that many of them were distributed in both lamina I and IIo in the SDH throughout spinal segments (Supplementary Fig. 1). We thus performed neurochemical characterization of c-fos-positive neurons in formalin-injected mice by SST, Pax2, and Brn3a (Fig. 3J-R), and the percentage of neurons positive for each marker among c-fos-positive neurons was analyzed. The percentage of SST- and Pax2-positive neurons among c-fos-positive ones in formalin-injected mice was comparable to that in DSS-treated mice (Fig. 3S left and 3T left). By contrast, the percentage of Brn3a-positive neurons among c-fos-positive ones was significantly higher in DSS-treated mice than in formalin model (Fig. 3U left). Similar result was obtained among c-fos-H-positive populations (Fig. 3S-U right). These results raised a possibility that Brn3a-positive neurons in the marginal lamina make a large contribution to the transmission of visceral pain in DSS-treated mice.

\section{Characterization of Brn3a-positive neurons in the spinal dorsal horn}

Although expression of Brn3a in the spinal dorsal horn has long been known [24], the identity of Brn3a-positive neurons has yet to be characterized. We thus 
assessed the expression of several molecular markers in Brn3a-positive neurons, such as Pax2, preprodynorphin (Pdyn), and cholecystokinin (CCK) (Fig. 4). Brn3a-positive neurons were almost never co-localized with Pax2 (Fig. 4A-C, 0.7\%, $n=2$ mice, 158 cells) both in the marginal and the deeper laminae, suggesting they were excitatory neurons. Pdyn, which marks a population of excitatory and inhibitory neurons in lamina I and II [25], was positive in $45.4 \pm 6.1 \%$ of Brn3a-positive neurons in the marginal lamina (Fig. 4D-F, $n=3$ mice, 251 cells). CCK, a marker of a population of excitatory neurons in lamina III and IV [26], was positive in 50.9\% of Brn3a-positive neurons in deeper laminae (Fig. 4G-I, $n=2$ mice, 186 cells), but it was not expressed in Brn3a-positive neurons localized in the marginal lamina ( $0 \%, n=2$ mice, 35 cells). These results suggest that Brn3a-positive neurons in the marginal lamina are excitatory neurons and are neurochemically different from Brn3a-positive neurons localized in the deeper laminae.

Since supraspinal projection neurons transmitting nociceptive information are highly accumulated in the marginal lamina [27], we wondered whether Brn3a-positive neurons localized in this area, included supraspinal projection neurons. We first focused on spino-parabrachial neurons innervating lateral parabrachial nucleus ( $\mathrm{LPb})$ in the pons, which constitute about $90 \%$ of total supraspinal projection neurons transmitting 
nociceptive signal [27]. These neurons were labeled by injection of the retrograde axonal tracer cholera toxin B (CTB) into LPb (Supplementary Fig. 2), and the spinal cord of injected mice was immunostained with antibodies against CTB together with Brn3a to analyze their co-localization (Fig. 5A-C). Contrary to our expectations, the percentage of Brn3a-positive neurons among spino-parabrachial projection ones in the marginal lamina was low at the lumbar level $(14.5 \pm 0.6 \%, n=3$ mice, 172 cells $)$. We next examined spino-solitary projection neurons [28] (Supplementary Fig. 2) since their axonal target, the nucleus of the solitary tract (NTS), is involved in the processing of visceral sensory information, although their visceral inputs has been assumed to be transmitted via the vagus nerve [29]. Interestingly, the percentage of Brn3a-positive neurons among spino-solitary projection ones in the marginal lamina was $51.8 \pm 4.6 \%$ at the lumbar level (Fig. 5D-G, $n=6$ mice, 166 cells), which was significantly higher than that among spino-parabrachial projection neurons $(p=0.0238$, Mann-Whitney $\mathrm{U}$ test). Similar results were obtained in the thoracic spinal cord of the mice, in which 16.8 $\pm 2.5 \%$ ( $n=3$ mice, 97 cells) of spino-parabrachial projection neurons in the marginal lamina was Brn3a-positve versus $59.0 \pm 9.9 \%$ ( $n=3$ mice, 71 cells $)$ of spino-solitary projection neurons being Brn3a-positive (Supplementary Fig. 3).

Preferential activation of Brn3a-positive spinal dorsal horn neurons in 
DSS-treated mice (Fig. 3) together with enrichment of Brn3a in the spino-solitary projection neurons (Fig. 5) imply that visceral pain transmission through these projection neurons strongly relies on Brn3a-positive population. To examine this possibility, we labeled spino-solitary projection neurons by CTB in DSS-treated mice to assess the percentage of Brn3a-positive neurons among visceral pain-responsive spino-solitary projection neurons (Fig. 6). In accordance with the abundance of Brn3a-positive neurons in the spino-solitary projection neurons (Fig. 5), $57.4 \pm 4.7 \%$ ( $n$ $=3$ mice, 57 cells) of c-fos- and CTB-double-positive neurons in the marginal lamina were Brn3a-positive. Collectively, these results suggest that a population of Brn3a-positive neurons in the marginal lamina of the spinal dorsal horn contributes to the visceral pain transmission to NTS. 


\section{Discussion}

In this study, we took advantage of IBD model mice generated by DSS treatment and analyzed their visceral pain transmission in the spinal dorsal horn. Analyses of neural activity in the spinal dorsal horn of these mice demonstrated that visceral pain preferentially evokes activities of Brn3a-positive neurons for its transmission. We further uncovered that a population of the Brn3a-positive neurons in the marginal lamina were engaged in visceral pain transmission to the nucleus of the solitary tract.

\section{DSS-treated mice as a visceral pain model}

Neural circuits in the spinal dorsal horn transmitting visceral pain have been less studied compared to those of somatic sensation, possibly because of the lack of proper experimental models together with difficulty in evaluating behavioral responses.

DSS-treated mice have been employed in some previous studies on visceral pain in the proximal colon as DSS treatment enhanced visceral pain sensitivity to several stimulants injected into the colon $[30,31]$. Our study went a step further to show that DSS treatment itself was enough to evoke visceral nociceptive behavior (Fig. 1B and 1C) and neuronal activities in the spinal dorsal horn (Fig. 2). This is at least partly due 
to our choice of using C57BL/6 mice which exhibit higher susceptibility to DSS [17,

18]. Rostro-caudal and laminar localization pattern of c-fos-positive neurons in the spinal cord of DSS-treated mice (Figs. 2 and 3) resembles that observed in acute visceral pain models, including mechanical distension of proximal colon [7] and lower urinary tract [5]. Thus, our DSS-treated mouse model is an addition to the list of visceral pain models, and has an added value of having minimum risk of induction of artificial somatic stimulation which sometimes occurs in the experimental procedure of mechanical distension of the colon [30].

\section{Involvement of Brn3a-positive spinal dorsal horn neurons in the transmission of visceral pain-specific signal}

Our study demonstrated that the percentage of Brn3a-positive neurons among visceral pain-responsive neurons was significantly higher than that among somatic pain-responsive ones (Fig. 3U). This is in line with the preferential localization of visceral pain-responsive neurons in the marginal lamina of the shallow dorsal horn (Fig. 2D-G). These results suggest that visceral pain preferentially activates Brn3a-positive neurons for its transmission. Considering a previous study showing that almost all visceral pain-responsive neurons also receive somatic sensory inputs [4], it is highly 
possible that Brn3a-positive neurons responsive to visceral pain stimulation are also viscero-somatic neurons. This might explain that a few percentage of c-fos-positive neurons in formalin-injected mice were also Brn3a-positive (18.1 $\pm 1.9 \%$, Fig. 3U). In fact, the absolute number of Brn3a- and c-fos-double positive neurons in formalin-injected mice was comparable to that in DSS-treated mice (data not shown). Hence, it is conceivable that activation of viscero-somatic Brn3a-positive neurons would mainly contribute to the induction of visceral pain-related sensation, while activation of these neurons together with neurons responsive only to somatic pain (e.g. lamina II neurons) would induce somatic pain sensation. However, we cannot exclude the possibility that some populations of Brn3a-positive neurons respond to visceral or somatic stimulation only. Further electrophysiological or calcium imaging studies on Brn3a-positive neurons following visceral and somatic stimulation would be needed to characterize the identity of these neurons.

\section{Visceral pain transmission to the higher brain center}

The current study demonstrated that Brn3a-positive neurons were highly represented in spino-solitary projection neurons responsive to visceral pain stimulation, although we did not characterize the other populations of visceral pain-evoked 
Brn3a-positive neurons in the spinal dorsal horn (Fig. 7). One possibility is that they might belong to the propriospinal neurons which interconnect distant spinal segments. In support of this notion, most neurons expressing Brn3a and related transcription factors (Brn3b and Brn3c) in the central and peripheral nervous system are long-range neurons [32]. Thus, it is possible that Brn3a-positive neurons in the spinal dorsal horn may be involved in the long-range sensory transmission including both supraspinal and propriospinal pathway.

Among the supraspinal projection neurons examined in this study (Fig. 5G), Brn3a-positive neurons were highly enriched in spino-solitary neurons $(51.8 \pm 4.6 \%)$ but not in spino-parabrachial projection ones $(14.5 \pm 0.6 \%)$, even though lateral parabrachial nucleus $(\mathrm{LPb})$ is the principal axonal target of supraspinal projection neurons [27]. Almost all ( 90\%) spino-solitary projection neurons were shown to send collateral projections to $\mathrm{LPb}$ whereas projection neurons innervating both NTS and LPb accounted for only a quarter of spino-parabrachial projection neurons [33](Supplementary Fig. 4). This fact suggests that supraspinal projection neurons can be largely divided into two populations in terms of projection toward NTS and $\mathrm{LPb}$ : one innervates both NTS and $\mathrm{LPb}$, and the other only $\mathrm{LPb}$. Based on the abundance of these neurons [33], the percentage of Brn3a-positive neurons among the latter population 
(spino-parabrachial only neurons) can be estimated to be $3.67 \%$ (Supplementary Fig. 4), further indicating that Brn3a-positive neurons are enriched in projection neurons innervating both NTS and $\mathrm{LPb}$ compared to those innervating only $\mathrm{LPb}$. Simultaneous activation of NTS and LPb by Brn3a-positive projection neurons might be crucial for visceral pain transmission.

NTS sends axonal projections to many brain areas such as ventrolateral medulla, parabrachial nucleus (PB), periaqueductal gray (PAG), hypothalamus, and amygdala [34]. Based on its connectivity, NTS is commonly assumed to play the autonomic-affective function. Cardiovascular regulation of NTS through the control of sympathetic premotor neurons in the rostral ventrolateral medulla (RVLM) has been well documented [35]. Tachycardia evoked by nociceptive stimulation was shown to be suppressed by synaptic inhibition of NTS neurons [36], raising a possibility that visceral pain signal via spino-solitary pathway is involved in the regulation of cardiac function.

On the other hand, NTS innervation to amygdala suggests a role of spino-solitary pathway in the transmission of an emotional aspect of visceral pain.

Since the vagal afferent nerve is an important mediator of viscerosensory transmission to NTS [37], it is highly possible that NTS functions as an integration center of visceral information through vagal and spino-solitary afferents. In addition, 
involvement of post synaptic dorsal column (PSDC) neurons, which is localized outside the shallow dorsal horn, in the visceral pain transmission has long been known [10, 11]. PSDC neurons send axonal projection directly toward the gracile nucleus in the medulla, whose lesion attenuates certain types of visceral pain. In order to fully understand visceral pain transmission, we need to elucidate the function of each of these pathways as well as the mechanisms that integrate their information in the higher brain center. 


\section{Acknowledgements}

We thank Drs. N. Funatsu, S. Iki, A. Inoue, T. Katano, and R. Suno for their technical advices; Drs. N. Funatsu, A. Inoue, T. Katano for materials; and Dr. Y. Zhu for critical reading of the manuscript. This study was supported by a grant-in-aid (19K07855) for scientific research from the Ministry of Education, Science, Sports and Culture of Japan.

\section{Conflict of Interest Statement}

The authors declare no conflicts of interest associated with this manuscript.

\section{Authors' Contributions}

$\mathrm{KN}$ designed the research, performed the experiments, analyzed the data, and wrote the manuscript. SM contributed analytic tools and stereotactic surgery. TK contributed discussion and suggestion. 


\section{References}

1. Sengupta JN. Visceral pain: the neurophysiological mechanism. Handb Exp

Pharmacol. 2009;(194):31-74. Epub 2009/08/06. doi: 10.1007/978-3-540-79090-7_2.

PubMed PMID: 19655104; PubMed Central PMCID: PMCPMC3156094.

2. Duan B, Cheng L, Ma Q. Spinal Circuits Transmitting Mechanical Pain and

Itch. Neurosci Bull. 2018;34(1):186-93. Epub 2017/05/10. doi:

10.1007/s12264-017-0136-z. PubMed PMID: 28484964; PubMed Central PMCID:

PMCPMC5799122.

3. Cervero F, Laird JM. Visceral pain. Lancet. 1999;353(9170):2145-8. Epub 1999/06/26. doi: 10.1016/S0140-6736(99)01306-9. PubMed PMID: 10382712.

4. Cervero F. Somatic and visceral inputs to the thoracic spinal cord of the cat: effects of noxious stimulation of the biliary system. J Physiol. 1983;337:51-67. Epub 1983/04/01. doi: 10.1113/jphysiol.1983.sp014611. PubMed PMID: 6875945; PubMed Central PMCID: PMCPMC1199094.

5. Birder LA, de Groat WC. Increased c-fos expression in spinal neurons after irritation of the lower urinary tract in the rat. J Neurosci. 1992;12(12):4878-89. Epub 1992/12/01. PubMed PMID: 1464772; PubMed Central PMCID: PMCPMC6575764.

6. Traub RJ, Pechman P, Iadarola MJ, Gebhart GF. Fos-like proteins in the 
lumbosacral spinal cord following noxious and non-noxious colorectal distention in the rat. Pain. 1992;49(3):393-403. Epub 1992/06/01. doi: 10.1016/0304-3959(92)90247-9.

PubMed PMID: 1408305.

7. Martinez V, Wang L, Mayer E, Tache Y. Proximal colon distention increases Fos expression in the lumbosacral spinal cord and activates sacral parasympathetic NADPHd-positive neurons in rats. J Comp Neurol. 1998;390(3):311-21. Epub 1998/02/10. PubMed PMID: 9455894.

8. Laird JM, Roza C, Cervero F. Spinal dorsal horn neurons responding to noxious distension of the ureter in anesthetized rats. $\mathrm{J}$ Neurophysiol. 1996;76(5):3239-48. Epub 1996/11/01. doi: 10.1152/jn.1996.76.5.3239. PubMed PMID: 8930269.

9. Luz LL, Fernandes EC, Sivado M, Kokai E, Szucs P, Safronov BV. Monosynaptic convergence of somatic and visceral C-fiber afferents on projection and local circuit neurons in lamina I: a substrate for referred pain. Pain. 2015;156(10):2042-51. Epub 2015/06/23. doi: 10.1097/j.pain.0000000000000267. PubMed PMID: 26098437; PubMed Central PMCID: PMCPMC4770360.

10. Al-Chaer ED, Lawand NB, Westlund KN, Willis WD. Visceral nociceptive input into the ventral posterolateral nucleus of the thalamus: a new function for the 
dorsal column pathway. J Neurophysiol. 1996;76(4):2661-74. Epub 1996/10/01. doi: 10.1152/jn.1996.76.4.2661. PubMed PMID: 8899636.

11. Willis WD, Al-Chaer ED, Quast MJ, Westlund KN. A visceral pain pathway in the dorsal column of the spinal cord. Proc Natl Acad Sci U S A. 1999;96(14):7675-9. Epub 1999/07/08. doi: 10.1073/pnas.96.14.7675. PubMed PMID: 10393879; PubMed Central PMCID: PMCPMC33600.

12. Laird JMA, Martinez-Caro L, Garcia-Nicas E, Cervero F. A new model of visceral pain and referred hyperalgesia in the mouse. Pain. 2001;92(3):335-42. Epub 2001/05/30. doi: 10.1016/S0304-3959(01)00275-5. PubMed PMID: 11376906.

13. Takahashi Y, Chiba T, Kurokawa M, Aoki Y. Dermatomes and the central organization of dermatomes and body surface regions in the spinal cord dorsal horn in rats. J Comp Neurol. 2003;462(1):29-41. Epub 2003/05/23. doi: 10.1002/cne.10669. PubMed PMID: 12761822.

14. Nishida K, Ito S. Developmental origin of long-range neurons in the superficial dorsal spinal cord. Eur J Neurosci. 2017;46(10):2608-19. Epub 2017/10/05. doi: 10.1111/ejn.13736. PubMed PMID: 28977701.

15. Nishida K, Hoshino M, Kawaguchi Y, Murakami F. Ptf1a directly controls expression of immunoglobulin superfamily molecules Nephrin and Neph3 in the 
developing central nervous system. J Biol Chem. 2010;285(1):373-80. Epub 2009/11/06. doi: 10.1074/jbc.M109.060657. PubMed PMID: 19887377; PubMed Central PMCID: PMCPMC2804185.

16. Docherty MJ, Jones RC, 3rd, Wallace MS. Managing pain in inflammatory bowel disease. Gastroenterol Hepatol (N Y). 2011;7(9):592-601. Epub 2012/02/03. PubMed PMID: 22298998; PubMed Central PMCID: PMCPMC3264972.

17. Perse M, Cerar A. Dextran sodium sulphate colitis mouse model: traps and tricks. J Biomed Biotechnol. 2012;2012:718617. Epub 2012/06/06. doi: 10.1155/2012/718617. PubMed PMID: 22665990; PubMed Central PMCID: PMCPMC3361365.

18. Jain P, Hassan AM, Koyani CN, Mayerhofer R, Reichmann F, Farzi A, et al. Behavioral and molecular processing of visceral pain in the brain of mice: impact of colitis and psychological stress. Front Behav Neurosci. 2015;9:177. Epub 2015/07/29. doi: 10.3389/fnbeh.2015.00177. PubMed PMID: 26217204; PubMed Central PMCID: PMCPMC4498125.

19. Brierley SM, Hibberd TJ, Spencer NJ. Spinal Afferent Innervation of the Colon and Rectum. Front Cell Neurosci. 2018;12:467. Epub 2018/12/20. doi: 10.3389/fncel.2018.00467. PubMed PMID: 30564102; PubMed Central PMCID: 


\section{PMCPMC6288476.}

20. Gutierrez-Mecinas M, Furuta T, Watanabe M, Todd AJ. A quantitative study of neurochemically defined excitatory interneuron populations in laminae I-III of the mouse spinal cord. Mol Pain. 2016;12. Epub 2016/04/01. doi: 10.1177/1744806916629065. PubMed PMID: 27030714; PubMed Central PMCID:

\section{PMCPMC4946630.}

21. Larsson M. Pax2 is persistently expressed by GABAergic neurons throughout the adult rat dorsal horn. Neurosci Lett. 2017;638:96-101. doi: 10.1016/j.neulet.2016.12.015. PubMed PMID: WOS:000392787400016.

22. Todd AJ, Sullivan AC. Light microscope study of the coexistence of GABA-like and glycine-like immunoreactivities in the spinal cord of the rat. J Comp Neurol. 1990;296(3):496-505. Epub 1990/06/15. doi: 10.1002/cne.902960312. PubMed PMID: 2358549.

23. Xu Y, Lopes C, Qian Y, Liu Y, Cheng L, Goulding M, et al. Tlx1 and Tlx3 coordinate specification of dorsal horn pain-modulatory peptidergic neurons. J Neurosci. 2008;28(15):4037-46. Epub 2008/04/11. doi: 10.1523/JNEUROSCI.4126-07.2008. PubMed PMID: 18400903; PubMed Central PMCID: PMCPMC2681187.

24. Muller T, Brohmann H, Pierani A, Heppenstall PA, Lewin GR, Jessell TM, et al. 
The homeodomain factor lbx1 distinguishes two major programs of neuronal differentiation in the dorsal spinal cord. Neuron. 2002;34(4):551-62. Epub 2002/06/14. doi: 10.1016/s0896-6273(02)00689-x. PubMed PMID: 12062039.

25. Sardella TC, Polgar E, Garzillo F, Furuta T, Kaneko T, Watanabe M, et al. Dynorphin is expressed primarily by GABAergic neurons that contain galanin in the rat dorsal horn. Mol Pain. 2011;7:76. Epub 2011/10/01. doi: 10.1186/1744-8069-7-76. PubMed PMID: 21958458; PubMed Central PMCID: PMCPMC3192681.

26. Abraira VE, Kuehn ED, Chirila AM, Springel MW, Toliver AA, Zimmerman AL, et al. The Cellular and Synaptic Architecture of the Mechanosensory Dorsal Horn. Cell. 2017;168(1-2):295-310 e19. Epub 2017/01/04. doi: 10.1016/j.cell.2016.12.010. PubMed PMID: 28041852; PubMed Central PMCID: PMCPMC5236062.

27. Todd AJ. Neuronal circuitry for pain processing in the dorsal horn. Nat Rev Neurosci. 2010;11(12):823-36. Epub 2010/11/12. doi: 10.1038/nrn2947. PubMed PMID: 21068766; PubMed Central PMCID: PMCPMC3277941.

28. Menetrey D, Basbaum AI. Spinal and trigeminal projections to the nucleus of the solitary tract: a possible substrate for somatovisceral and viscerovisceral reflex activation. J Comp Neurol. 1987;255(3):439-50. Epub 1987/01/15. doi: 10.1002/cne.902550310. PubMed PMID: 3819024. 
29. Coote JH, Spyer KM. Central control of autonomic function. Brain Neurosci Adv. 2018;2:2398212818812012. Epub 2018/11/13. doi: 10.1177/2398212818812012. PubMed PMID: 32166159; PubMed Central PMCID: PMCPMC7058216.

30. Eijkelkamp N, Kavelaars A, Elsenbruch S, Schedlowski M, Holtmann G, Heijnen CJ. Increased visceral sensitivity to capsaicin after DSS-induced colitis in mice: spinal cord c-Fos expression and behavior. Am J Physiol Gastrointest Liver Physiol. 2007;293(4):G749-57. Epub 2007/07/28. doi: 10.1152/ajpgi.00114.2007. PubMed PMID: 17656446.

31. Mitrovic M, Shahbazian A, Bock E, Pabst MA, Holzer P. Chemo-nociceptive signalling from the colon is enhanced by mild colitis and blocked by inhibition of transient receptor potential ankyrin 1 channels. Br J Pharmacol. 2010;160(6):1430-42. Epub 2010/07/02. doi: 10.1111/j.1476-5381.2010.00794.x. PubMed PMID: 20590633; PubMed Central PMCID: PMCPMC2938814.

32. Leyva-Diaz E, Masoudi N, Serrano-Saiz E, Glenwinkel L, Hobert O. Brn3/POU-IV-type POU homeobox genes-Paradigmatic regulators of neuronal identity across phylogeny. Wiley Interdiscip Rev Dev Biol. 2020;9(4):e374. Epub 2020/02/06. doi: 10.1002/wdev.374. PubMed PMID: 32012462.

33. Polgar E, Wright LL, Todd AJ. A quantitative study of brainstem projections 
from lamina I neurons in the cervical and lumbar enlargement of the rat. Brain Res.

2010;1308:58-67. Epub 2009/10/27. doi: 10.1016/j.brainres.2009.10.041. PubMed

PMID: 19854164; PubMed Central PMCID: PMCPMC2828548.

34. Kawai Y. Differential Ascending Projections From the Male Rat Caudal

Nucleus of the Tractus Solitarius: An Interface Between Local Microcircuits and Global

Macrocircuits. Front Neuroanat. 2018;12:63. Epub 2018/08/09. doi:

10.3389/fnana.2018.00063. PubMed PMID: 30087599; PubMed Central PMCID:

PMCPMC6066510.

35. Cutsforth-Gregory JK, Benarroch EE. Nucleus of the solitary tract, medullary

reflexes, and clinical implications. Neurology. 2017;88(12):1187-96. Epub 2017/02/17.

doi: 10.1212/WNL.0000000000003751. PubMed PMID: 28202704.

36. Boscan P, Pickering AE, Paton JF. The nucleus of the solitary tract: an integrating station for nociceptive and cardiorespiratory afferents. Exp Physiol. 2002;87(2):259-66. Epub 2002/02/22. doi: 10.1113/eph8702353. PubMed PMID: 11856972.

37. Berthoud HR, Neuhuber WL. Functional and chemical anatomy of the afferent vagal system. Auton Neurosci. 2000;85(1-3):1-17. Epub 2001/02/24. doi: 10.1016/S1566-0702(00)00215-0. PubMed PMID: 11189015. 


\section{Figure legends}

\section{Figure 1. DSS-treated mice as a visceral pain model.}

(A) Experimental design of DSS-treated mice. Duration (B) and number (C) of abdominal licking behavior during a 30 min time window before (Pre) and after (Post) treatment with $2 \%$ DSS are shown. Horizontal bars indicate the median. Data were analyzed by Mann-Whitney U test. $* \mathrm{p}<0.05, * * * \mathrm{p}<0.001$.

Figure 2. c-fos-positive cells in the lumbosacral spinal cord in control and DSS-treated, mice.

(A, B) Distribution of c-fos-positive cells. c-fos immunostaining on the transverse sections of the lumbosacral spinal cords in 0\% DSS-treated (A) and 2\% DSS-treated (B) mice was performed, and distribution of c-fos-positive cells on six sections (20 $\mu \mathrm{m}$ in thickness, $800 \mu \mathrm{m}$ apart each other) from the lumbar ( L5, top) to the sacral $(\sim \mathrm{S} 2$, bottom) spinal cords in a representative mouse in each condition is shown. c-fos-positive cells are shown as red dots. White and gray matters in each section are shown in light yellow and grey colors, respectively. Scale, $500 \mu \mathrm{m}$. (C) Distribution pattern of c-fos-positive cells. The spinal cord was divided into shallow dorsal horn $(\mathrm{SDH})$, deep dorsal horn (DDH), ventral horn (VH), and lateral funiculus (LF) (see 
materials and methods). Distribution of c-fos-positive cells in these areas in DSS-treated mice ( $n=4$ mice, 1205 cells) is shown in pai chart. (D-G) Transverse sections of the spinal dorsal horn of DSS-treated mice were immunostained with anti-c-fos (magenta) together with anti-PKC $\gamma$ (green) antibodies. Images on the right dorsal horn around L6 (D, E) and S1 (F, G) segments are shown. Scale, $100 \mu \mathrm{m}$.

Figure 3. Immunostaining of c-fos together with several molecular markers in the spinal cord of DSS-treated and formalin-injected mice.

c-fos immunostaining together with somatostatin (SST) in situ hybridization (A-C, J-L), or Pax2 (D-F, M-O) or Brn3a (G-I, P-R) immunostaining were performed on transverse sections of the lumbosacral spinal dorsal horn of DSS-treated (A-I) and formalin-injected (J-R) mice. Images of c-fos immunostaining (magenta; A, C, D, F, G, I, J, L, M, O, P, R), SST in situ hybridization (green; B, C, K, L), Pax2 immunostaining (green; E, F, N, O), or Brn3a immunostaining (green; H, I, Q, R) on the right spinal dorsal horn are shown. Open arrowheads indicate c-fos single-positive cells, whereas closed arrowheads indicate cells positive for both c-fos and marker molecules. Scale, $100 \mu \mathrm{m} .(\mathrm{S}, \mathrm{T}, \mathrm{U})$ Percentage of $S S T$ (S)-, Pax2 (T)-, and Brn3a (U)-positive cells among c-fos-positive cells is shown. c-fos-positive cells were classified into two 
categories: "c-fos-H" cells include those with strong c-fos intensity, whereas c-fos cells include those with both weak and strong c-fos intensity (see materials and methods). (S) The percentage of SST-positive cells among c-fos cells $(17.6 \pm 1.7 \%, n=6$ DSS-treated mice, 573 cells; $18.9 \pm 1.6 \%, n=4$ formalin-injected mice, 758 cells) and c-fos-H cells $(21.2 \pm 2.2 \%, n=6$ DSS-treated mice, 230 cells; $19.0 \pm 2.3 \%, n=4$ formalin-injected mice, 421 cells) is shown. (T) The percentage of Pax2-positive cells among c-fos cells $(31.8 \pm 1.4 \% n=5$ DSS-treated mice, 1548 cells; $27.2 \pm 1.3 \%, n=4$ formalin-injected mice, 1484 cells $)$ and c-fos-H cells $(42.0 \pm 1.4 \%, n=5$ DSS-treated mice, 488 cells; $43.4 \pm 3.3 \%, n=4$ formalin-injected mice, 859 cells) is shown. (U) The percentage of Brn3a-positive cells among c-fos cells $(30.4 \pm 2.6 \%, n=5$ DSS-treated mice, 1141 cells; $18.1 \pm 1.9 \%, n=4$ formalin-injected mice, 1458 cells $)$ and c-fos-H cells $(38.1 \pm$ $5.3 \%, n=5$ DSS-treated mice, 324 cells; $17.5 \pm 1.6 \%, n=4$ formalin-injected mice, 807 cells) is shown. Horizontal bars indicate the median. Data were analyzed by Mann-Whitney U test. ns means non-significant. *p $<0.05$.

Figure 4. Characterization of Brn3a-positive neurons in the spinal dorsal horn by co-immunostaining with several markers.

Brn3a immunostaining together with Pax2 immunostaining, or preprodynorphin (Pdyn) 
or cholecystokinin $(C C K)$ in situ hybridization were performed on transverse sections of the lumbosacral spinal dorsal horn of wild-type mice. (A, D, G) Low magnification images of Brn3a immunostaining (magenta) on the left spinal dorsal horn are shown. White dotted lines indicate the boundary between white and gray matters. (B, C) High magnification views (marked in A) of Brn3a signal with (C) or without (B) Pax2 signal (green) around the deep dorsal horn are shown. (E, F) High magnification views (marked in D) of Brn3a signal with (F) or without (E) Pdyn signal (green) around the shallow dorsal horn are shown. (H, I) High magnification views (marked in G) of Brn3a signal with (C) or without (B) $C C K$ signal (green) around the deep dorsal horn are shown. Closed arrowheads indicate cells with positive for Brn3a and markers, whereas open arrowhead indicates Brn3a-single-positive cell. Scale, $100 \mu \mathrm{m}$.

\section{Figure 5. Expression of Brn3a in the spino-parabrachial and spino-solitary}

\section{projection neurons.}

Spino-parabrachial (A-C) and spino-solitary (D-F) supraspinal projection neurons were labeled by injection of cholera toxin $\mathrm{B}(\mathrm{CTB})$ into the lateral parabrachial nucleus $(\mathrm{LPb})$ and the nucleus of the solitary tract (NTS), respectively. Immunostaining of CTB (magenta, B, C, E, F) together with Brn3a (green, C, F) was performed on transverse 
sections of the lumbar spinal dorsal horn of the mice. White dotted lines indicate the boundary between white and gray matters in the shallow dorsal horn. Closed and open arrowheads indicate CTB- and Brn3a-double and CTB-single-positive cells, respectively. Scale, $100 \mu \mathrm{m}$. (G) Percentage of Brn3a-postiive cells among spino-solitary $(51.8 \pm 4.6 \%, n=6$ mice, 166 cells $)$ and spino-parabrachial $(14.5 \pm 0.6 \%$, $n=3$ mice, 172 cells) supraspinal projection neurons is shown. Horizontal bars indicate the median. Data were analyzed by Mann-Whitney U test. *p $<0.05$.

\section{Figure 6. Expression of Brn3a in visceral pain-responsive spino-solitary projection}

\section{neurons.}

(A) Spino-solitary supraspinal projection neurons were labeled by injection of cholera toxin B (CTB) into the nucleus of the solitary tract (NTS) in DSS-treated mice. Immunostaining of CTB together with c-fos and Brn3a was performed on transverse sections of the lumbosacral spinal cord of the mice. (B) Low magnification image of CTB immunostaining (magenta) on the representative section is shown. White dotted lines indicate the outline of the spinal cord and the boundary between white and gray matters. (C-F) High magnification views (marked in B) of CTB (C and F, magenta), c-fos (D and F, green), and Brn3a (E and F, blue) immunostaining are shown. Closed 
arrowheads indicate CTB-, c-fos- and Brn3a-triple positive cells. Scale, $50 \mu \mathrm{m}$.

Figure 7. Schematic showing proposed neural circuits in the shallow dorsal horn

\section{for visceral and somatic pain.}

Visceral pain preferentially evokes neuronal activities of marginal (lamina I) lamina neurons in the spinal dorsal horn whereas somatic pain does those of both marginal and deeper laminae neurons (lamina II and III). Brn3a-positive neurons in the marginal lamina are one of the populations which preferentially responded to visceral pain. These neurons were highly represented among supraspinal projection neurons innervating NTS (spino-solitary projection neurons) compared to those innervating $\mathrm{LPb}$ (spino-parabrachial projection neurons). Note that most spino-solitary projection neurons also innervate $\mathrm{LPb}[33]$. 


\section{Figure 1}

A

Behavioral analysis

Fixation

DSS

treatment

Occult blood in stool

and diarrhea

Body weight loss

$\star \star \star$

B

Day 0 Day 4 Day 5 Day 6 Day 7,8

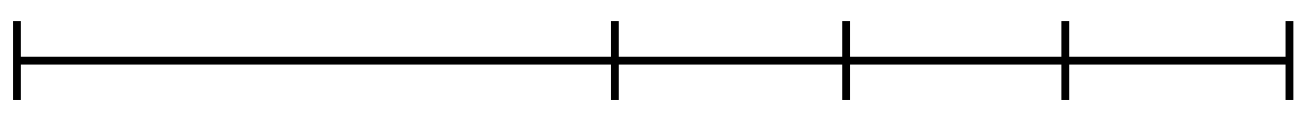

\section{and diarhea}
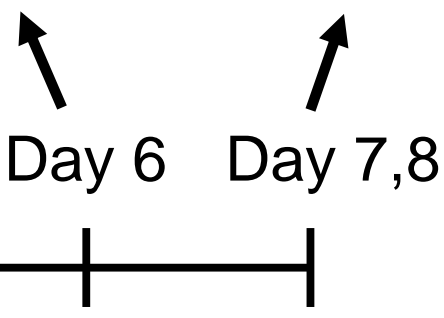


\section{Figure 2}

\section{A. Control B. DSS}

C. c-fos distribution
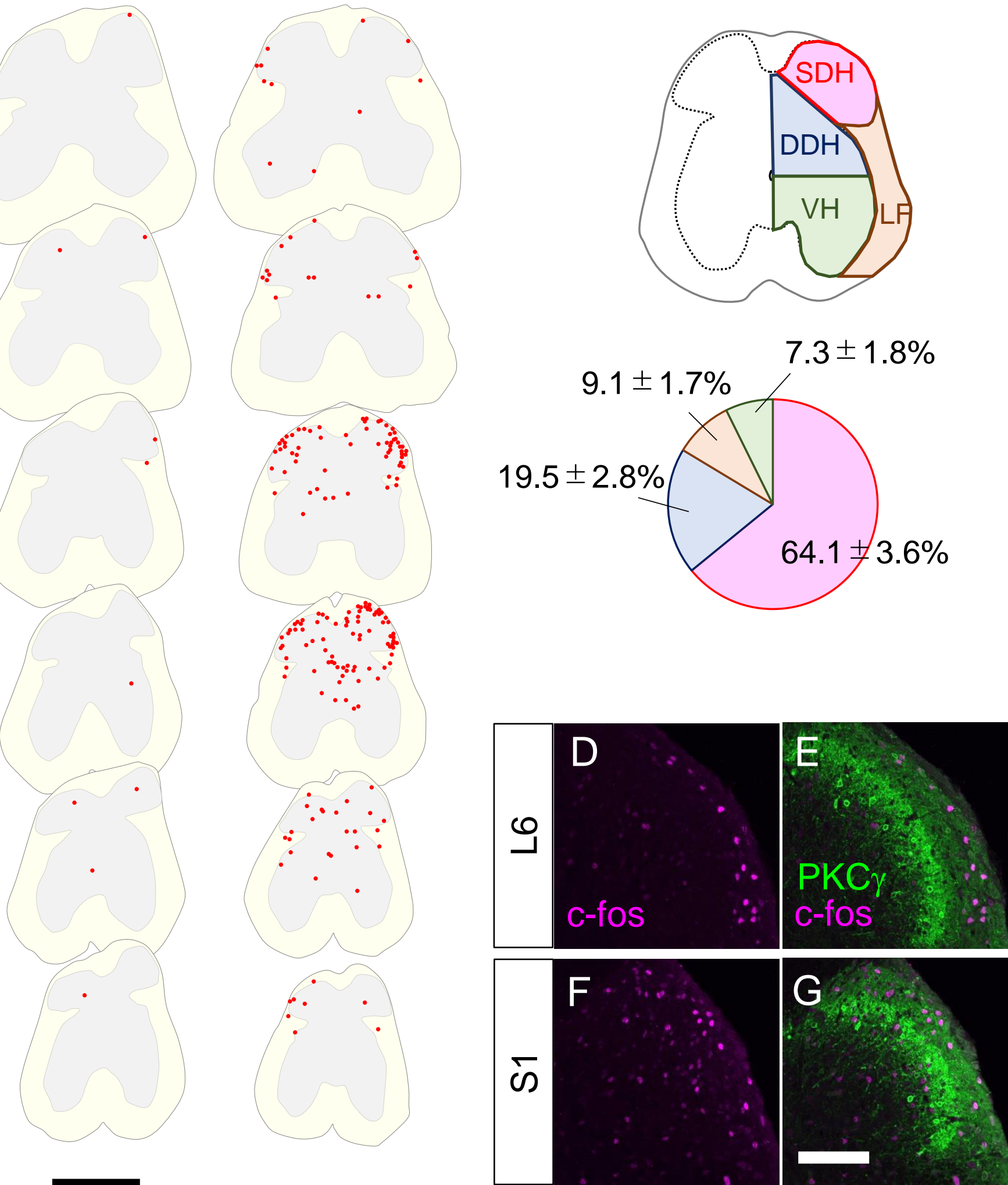


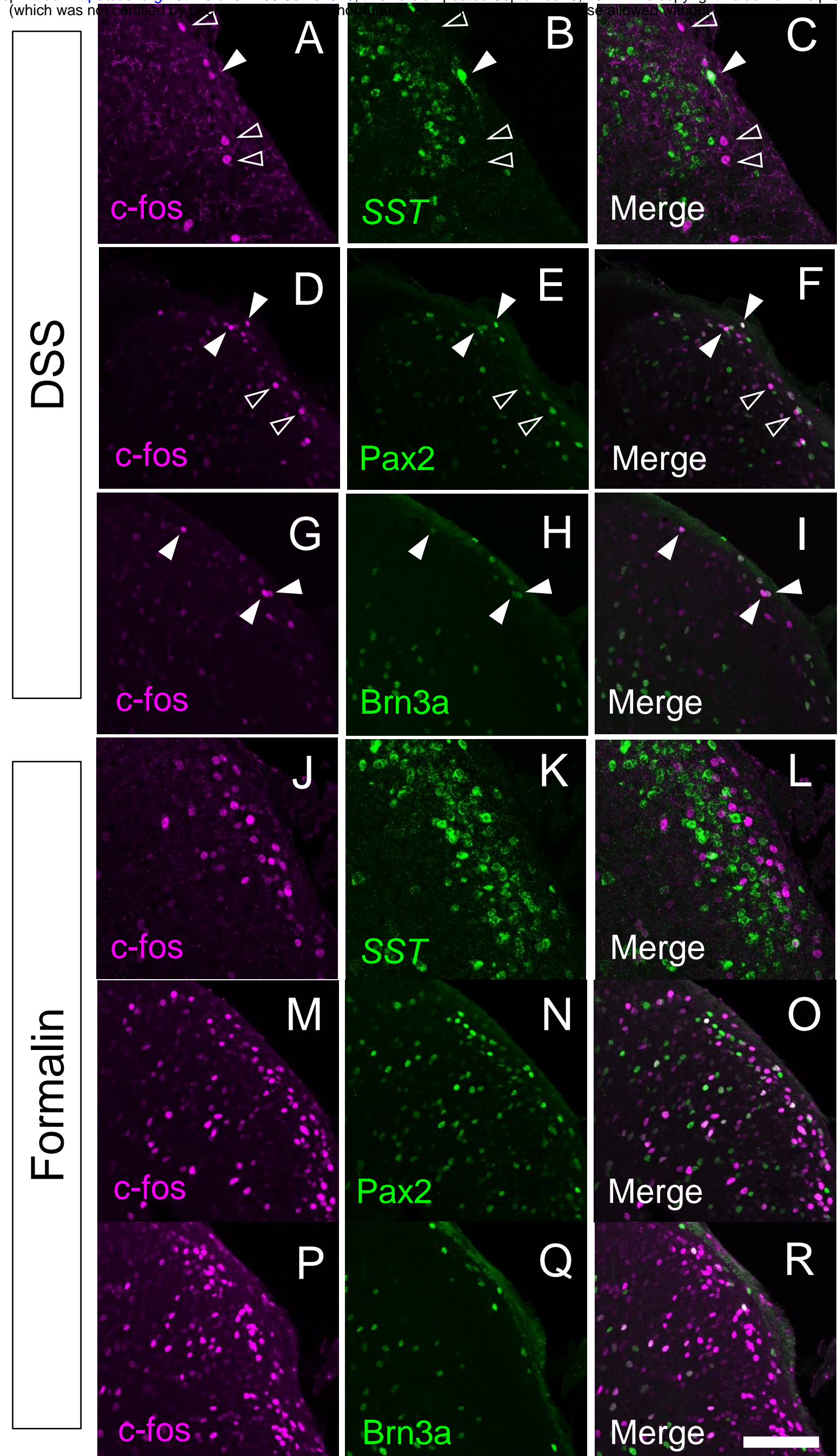




\section{(which was not certified by peer review) is the author/funder. All rights reserved. No reuse allowed without permission.}

\section{Figure 3}
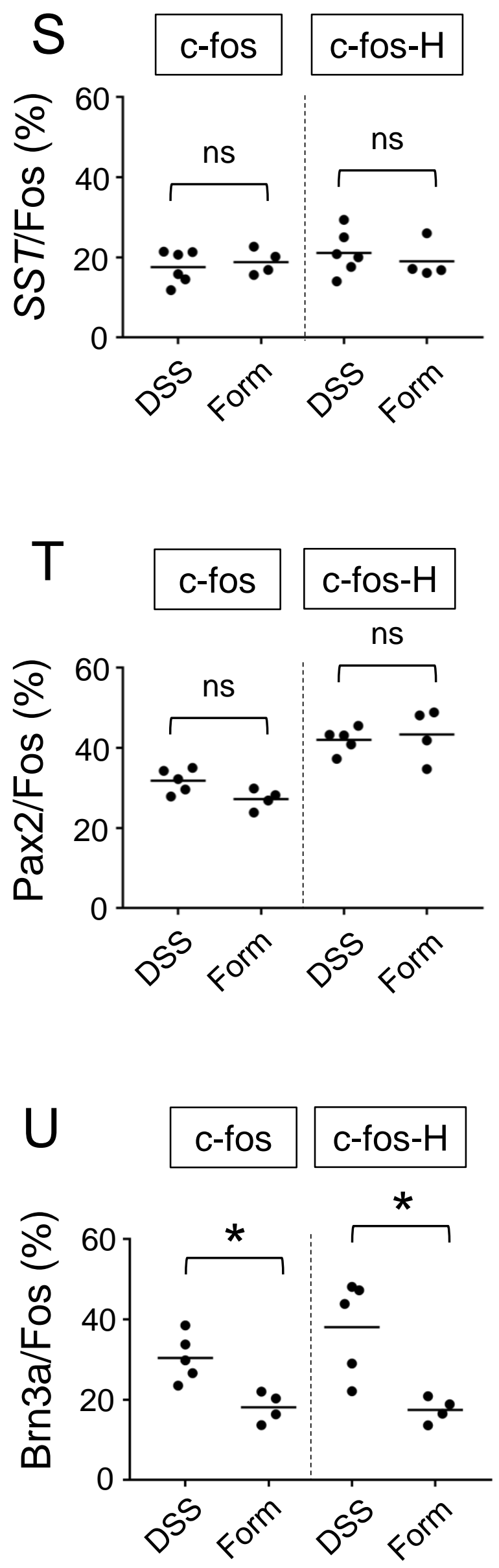


\section{Figure 4}
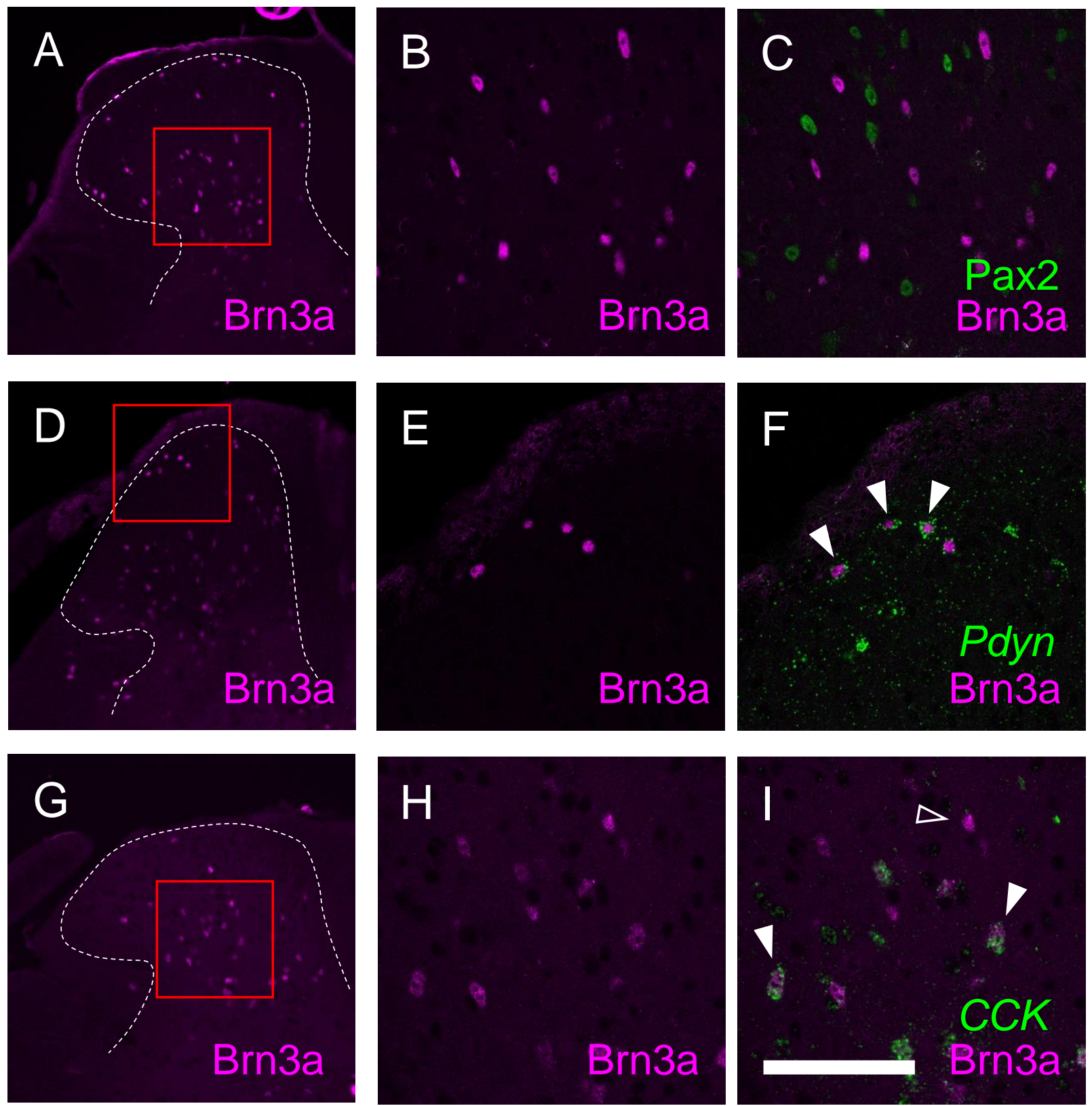


\section{(which was not certified by peer review) is the author/funder. All rights reserved. No reuse allowed without permission.}

Figure 5

A

Spinoparabrachial
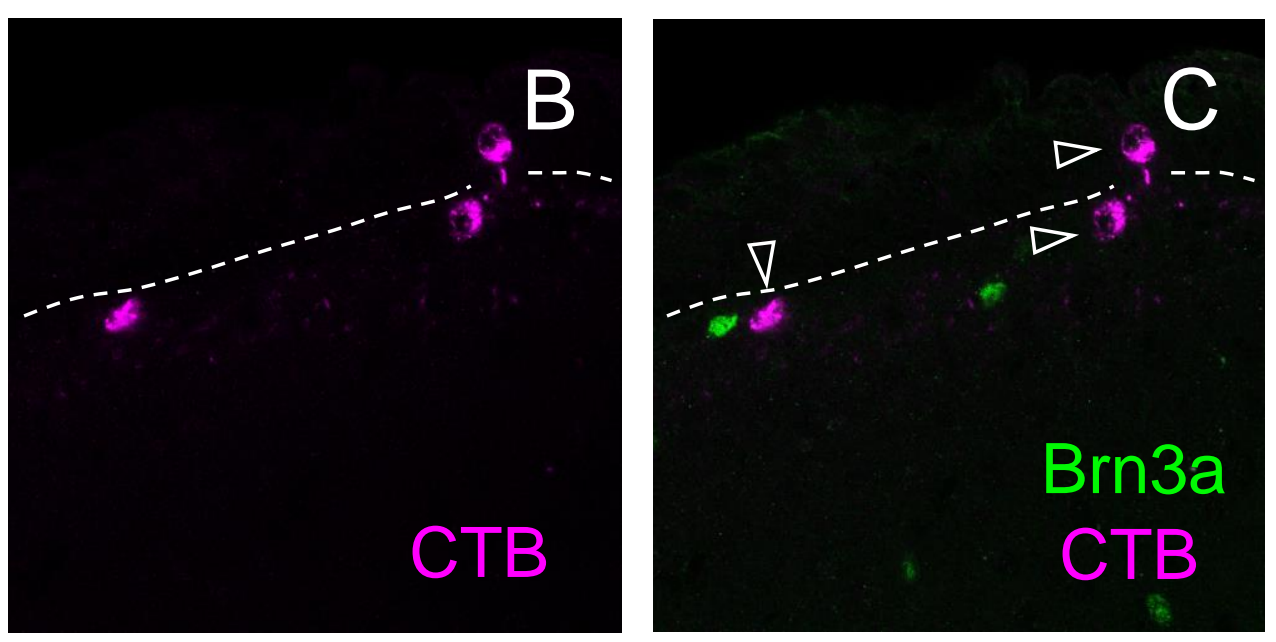

D
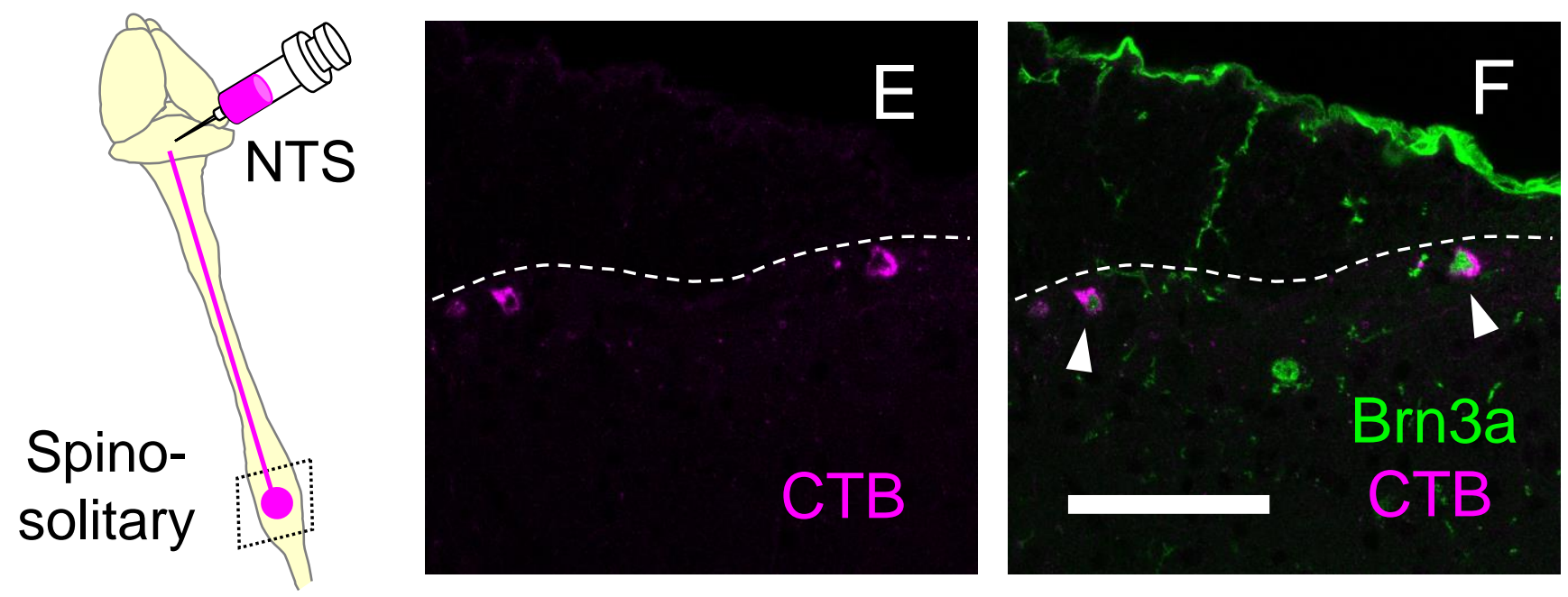

G

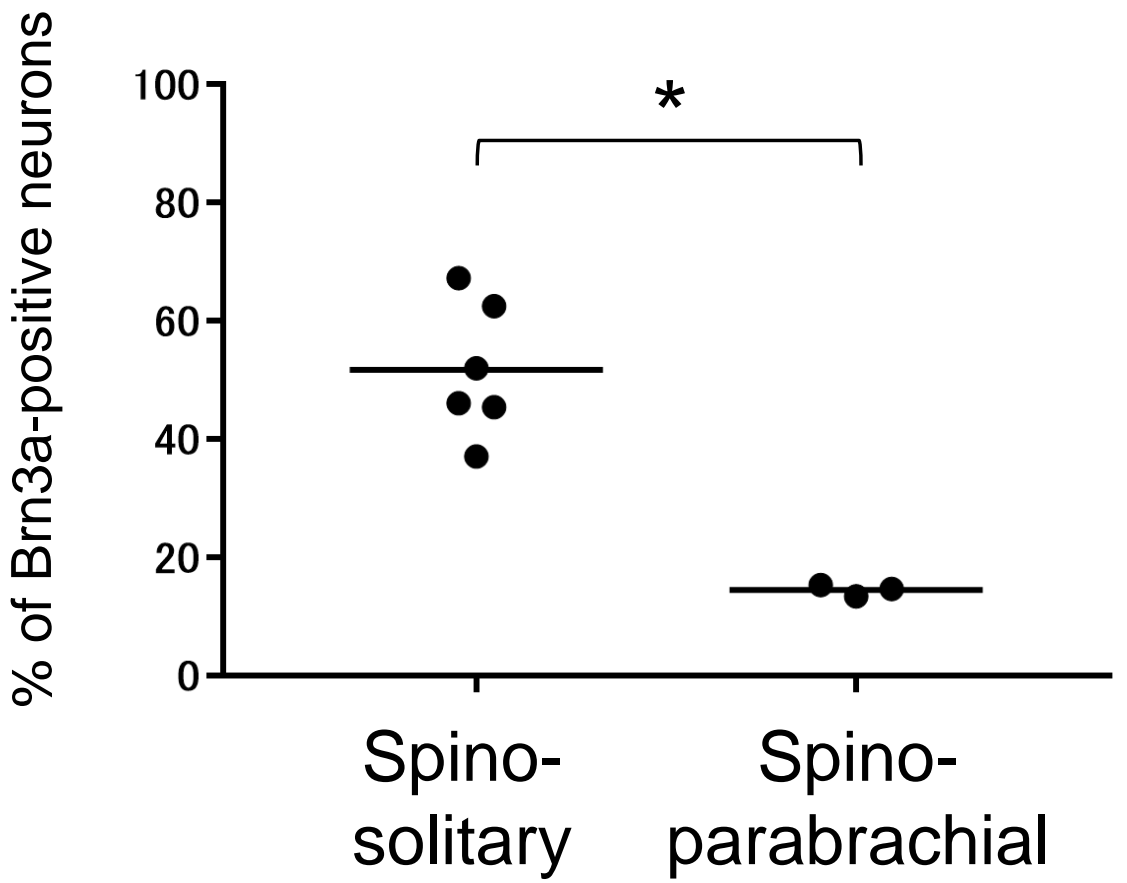




\section{Figure 6}
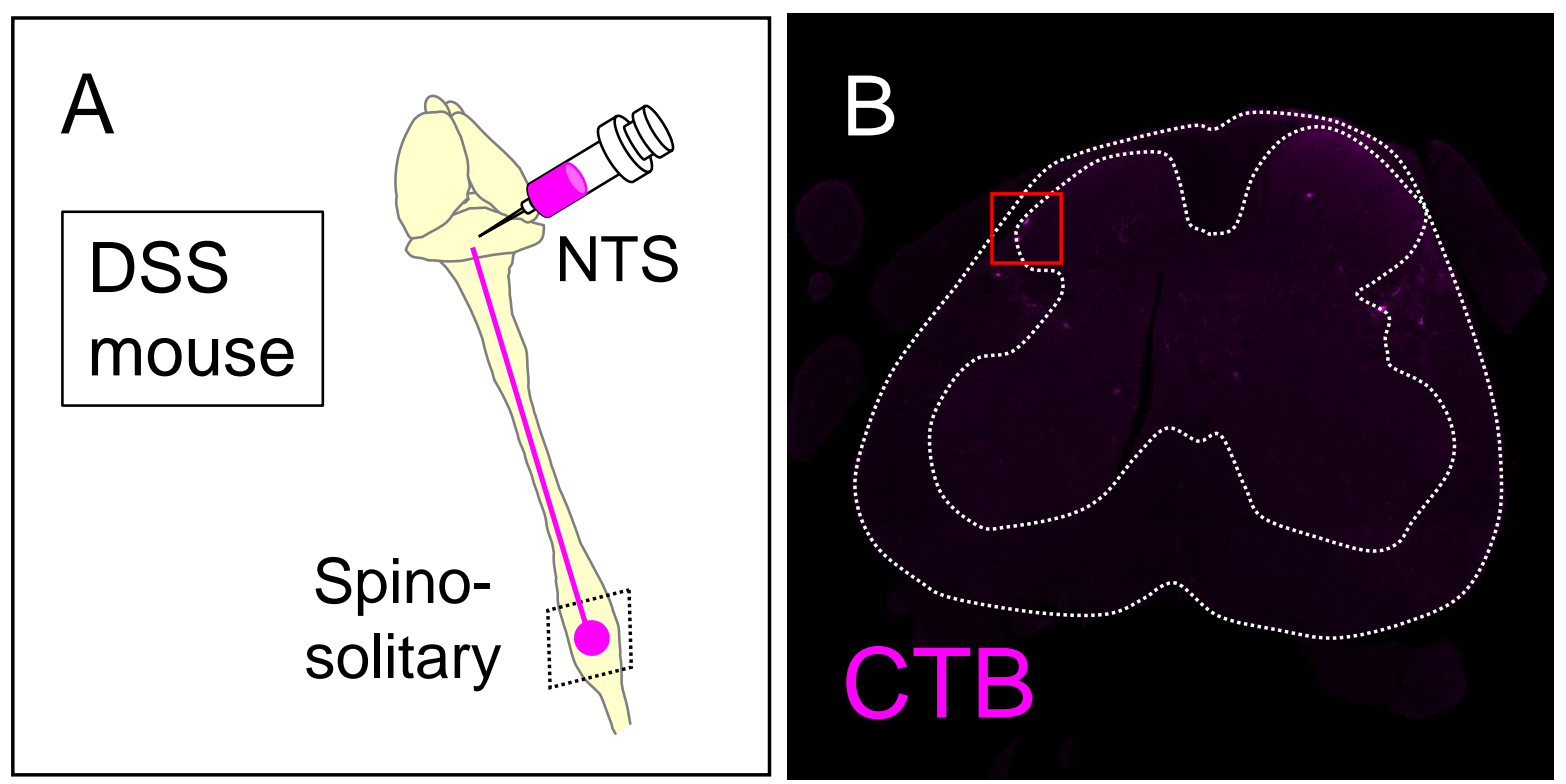

\section{C}

D

\section{c-fos}

\section{E}

F 


\section{. (which was not certified by peer review) is the author/funder. All rights reserved. No reuse allowed without permission.}

Figure 7

\section{Spinal cord}

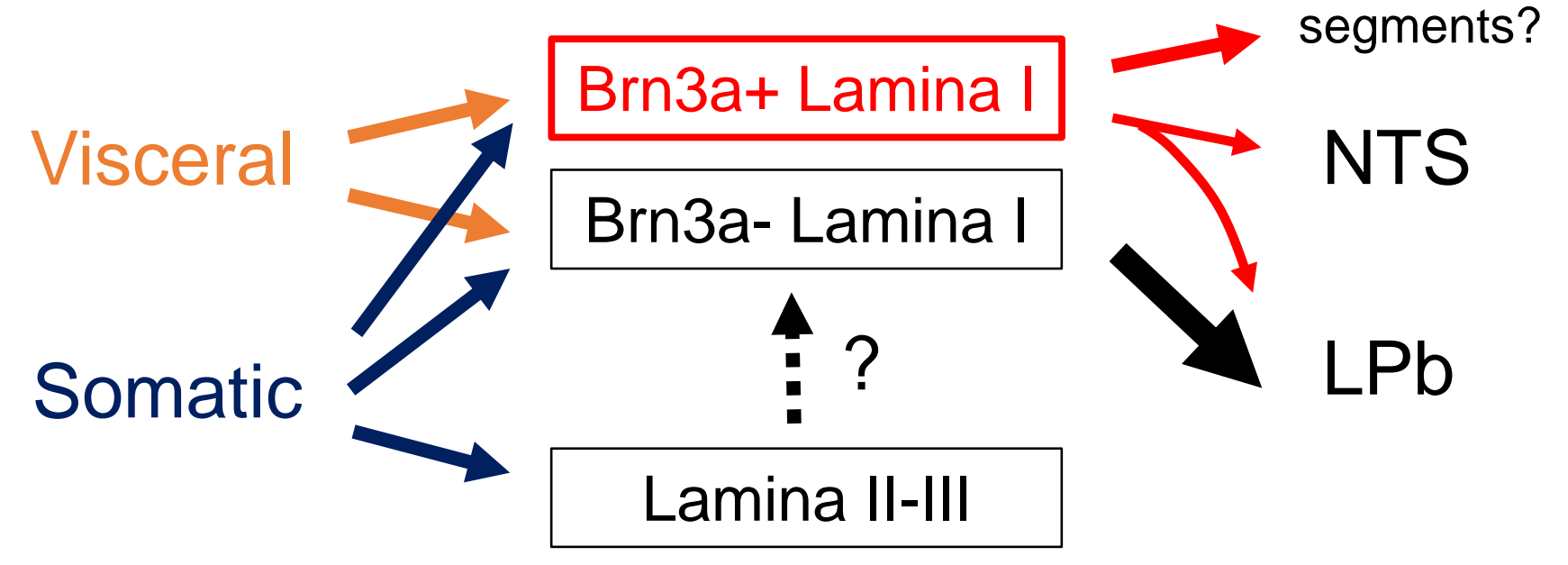

